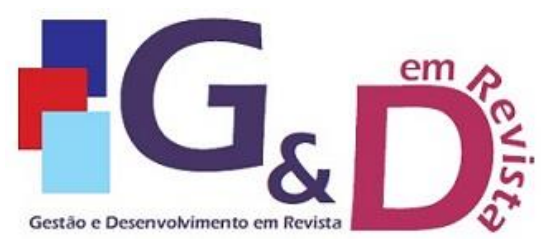

Gestão e Desenvolvimento em Revista V. 6, N. 1, jan-jun/2020, p. 46-59. ISSN online: $2446-8738$ Artigo recebido em: $20 / 04 / 2020$ Artigo aprovado em: 25/06/2020

\title{
AVALIAÇÃO DE DESEMPENHO DA ÁREA COMERCIAL: UM ESTUDO DE CASO EM UMA DISTRIBUIDORA DE EQUIPAMENTOS DE TECNOLOGIA
}

\author{
Diego de Lima Silva \\ Graduacão em Processos Gerenciais (QI). Mestrado em Direcão Comercial e Marketing (ENEB). \\ Atualmente é Gerente Geral de Compras na Mazer Distribuidora de Tecnologia Ltda. \\ E-mail: diegolima2103@gmail.com
}

\section{Vanessa Martins Pires}

Graduação em Administração e Ciências Contábeis. Mestrado em Ciências Contábeis. Doutorado em Administração. Atualmente é Professora Adjunta na Universidade Federal do Rio Grande (FURG) E-mail:vmpires@furg.br

\section{Resumo}

Dada a relevância da Tecnologia da Informação (TI) na economia brasileira e a importância da qualificação e do desempenho dos indivíduos, essa pesquisa buscou explorar os fatores que influenciaram no desempenho dos funcionários de uma das principais distribuidoras de $\mathrm{Tl}$ da região Sul do país. Através da análise de dados de desempenho de 15 vendedores foi possível identificar que os fatores que mais influenciaram positivamente no desempenho foram: Apresentação Pessoal, Organização, Relacionamento, Comprometimento e Negociação. Os fatores Produtividade e Resultados são aqueles que mais influenciaram negativamente. A empresa têm extraído bons resultados da sua equipe de vendas, já que aproximadamente $86 \%$ dos vendedores atingiram o desempenho mínimo esperado. A gestão da área de vendas tem adotado estratégias que estão alinhadas à teoria, que envolvem o controle e o monitoramento da equipe e a realização de feedbacks continuamente. O acompanhamento dos vendedores com desempenho aquém do esperado é realizada de forma acolhedora, característica que pode ser atribuída à gestão familiar da organização, que prioriza os vínculos (relacionamentos).

Palavras-chave: Avaliação de Desempenho. Tecnologia da Informação. Vendas.

\begin{abstract}
Given the relevance of Information Technology (IT) in the Brazilian economy and the importance of the qualification and performance of individuals, this research sought to explore the factors that influenced the performance of employees of one of the main IT distributors in the southern region of the country. Through the analysis of performance data from 15 salespeople it was possible to identify that the factors that most positively influenced performance were: Personal Presentation, Organization, Relationship, Commitment and Negotiation. The factors Productivity and Results are those that most negatively influenced. The company has been extracting good results from its sales team, as approximately $86 \%$ of salespeople have achieved the minimum expected performance. The management of the sales area has adopted strategies that are in line with the theory, which involve the control and the monitoring of the team and the realization of feedbacks continuously. The monitoring of salespeople with performance below expectations is carried out in a welcoming manner, a characteristic that can be attributed to the family management of the organization, which prioritizes bonds (relationships).
\end{abstract}

Keywords: Performance Evaluation. Information Technology. Sales. 


\section{INTRODUÇÃO}

O recurso mais valioso para as organizações são as pessoas, os talentos diversificados que imprimem sua marca nas atividades que executam no dia a dia. No mercado brasileiro, alguns segmentos corporativos têm demanda contínua de mão de obra qualificada. Dentre os segmentos que mais carecem de profissionais qualificados, encontra-se o segmento da Tecnologia da Informação (TI) (CHIQUIE, 2011).

A região Sul do Brasil tem a segunda maior contribuição no PIB do país, abriga um dos principais polos de empresas de Tecnologia da Informação e Comunicação (TICs), e é o maior celeiro para treinamento e desenvolvimento de profissionais da área de TI (GORDINHO, 2014). Sabe-se que a formação de profissionais especializados se dá de forma lenta e invariavelmente envolve alto custo. Diferentemente da formação universitária que provê ao indivíduo uma formação generalista, a qualificação do profissional dentro das empresas promove a especialização dos indivíduos em uma determinada área, propiciando um conhecimento com foco em produtividade.

Contudo, não basta apenas as empresas investirem os melhores recursos tecnológicos e altas somas de dinheiro, como condição única de alcançar seus objetivos estratégicos. A posse de tecnologia e recursos financeiros é relevante, mas o principal direcionador do desempenho das empresas são os recursos humanos e o seu know how (VOMBERG; HOMBURG; BORNEMANN, 2015; STARR; GANCO; CAMPBELL, 2018).

Encontrar pessoas qualificadas e certificadas na área da TI tem sido um grande desafio. $O$ segmento demanda pontualidade na entrega de projetos $\mathrm{e}$ solução de problemas em um mundo cada vez mais dependente da automatização e da informatização de dados, os quais refletem na melhoria de processos e na redução de custos (CHIQUIE, 2011).

O contexto atual do mercado demanda produtividade e liquidez nas organizações, o que exige a alocação estratégica dos recursos disponíveis, especialmente os recursos humanos. É necessário investir em treinamento e desenvolvimento, a fim de participar em uma posição de vanguarda no lançamento de novas tecnologias, considerando que tais investimentos devem ser materializados em resultado para as organizações (BAGAGl, 2016).

No Brasil, a distribuição de equipamentos de tecnologia é um mercado peculiar, com atuação nos mercados físicos e eletrônicos, envolvendo usuários finais, lojas revendedoras e grandes players do varejo, os quais utilizam os meios físico e eletrônico na geração das suas vendas. Compreendendo a relevância da $\mathrm{TI}$ na economia brasileira e a importância da qualificação e do desempenho dos seus colaboradores, essa pesquisa tem por objetivo identificar os fatores que influenciaram no desempenho dos funcionários de uma das principais distribuidoras de tecnologia da informação da região Sul do país. Por ser uma empresa distribuidora de tecnologia cuja atividade fim é a venda de produtos, a avaliação de desempenho da área comercial da empresa foi escolhida como objeto de análise.

Esta pesquisa é relevante por diferentes razões. Primeiramente, se justifica pela importância da performance dos recursos humanos no desempenho das organizações, relação amplamente discutida na literatura (GAMBARDELLA; PANICO; VALENTINI, 2015; MLLER; XU; MEHROTRA, 2015; STARR; GANCO; CAMPBELL, 2018). Em segundo lugar, os resultados obtidos trazem implicações 
gerenciais relevantes no contexto das empresas que comercializam produtos de $\mathrm{TI}$ no Brasil, cujo segmento é altamente competitivo e apresenta diferentes tendências de mercado, dentre elas: realidade virtual, internet das coisas, conectividade, inovação em telas e mercado gamer (GENISELLI, 2017). Por fim, a pesquisa se justifica pela baixa densidade de estudos empíricos sobre avaliação de desempenho dos colaboradores na literatura corporativa.

\section{FUNDAMENTAÇÃO TEÓRICA}

\section{1 ÁREA DE VENDAS}

A área de vendas de uma empresa é extremamente importante, pois é responsável pelo faturamento, proveniente da venda de produtos e/ou serviços. Os vendedores, representantes da área de vendas, são reconhecidos como o elo pessoal da empresa com os clientes e, muitas vezes, representam a empresa para o cliente (KOTLER, 2000).

As atribuições do cargo de vendedor variam significativamente em termos de natureza e pré-requisitos. Algumas empresas exigem que o vendedor apenas retire pedidos. Os tiradores de pedidos podem perguntar o que o cliente deseja ou simplesmente aguardar para tirar um pedido. Geralmente, não adotam estratégias de vendas e nem usam técnicas de abordagem, mas são importantes para o empregador que provavelmente não conseguiria alcançar seus objetivos sem o trabalho deles. Por outro lado, a venda criativa de bens tangíveis em mercados altamente competitivos, como o mercado de TI no Brasil, movimenta mercadorias que não podem ser vendidas em volume sem um profissional de vendas qualificado. A distribuição de equipamentos de tecnologia necessita de vendedores, aqueles profissionais que buscam concretizar novos pedidos frequentemente, usando uma estratégia de vendas bem definida e uma apresentação diferenciada (FUTRELL, 2003).

Para atingir os objetivos pretendidos pelas empresas que atuam no mercado de TI, os vendedores devem manter-se engajados e motivados. Parte do engajamento e motivação deve ser desenvolvido pelo gestor da área de vendas, o qual deve adequar às suas estratégias ao contexto de mercado da organização (FERREIRA; FRANCO, 2015).

\subsection{GESTÃO DA ÁREA DE VENDAS}

A literatura descreve que as empresas devem definir os objetivos a serem alcançados, e que esses objetivos serão quantificados em metas, as quais nortearão o trabalho dos vendedores (KOTLER, 2000).

Os gestores da área de vendas, por sua vez, devem ser capazes de convencer os vendedores de que eles podem obter melhores resultados através de capacitação e treinamento. Precisam conscientizar os vendedores de que o esforço extra é recompensando com uma melhor performance. Teoricamente, a gestão da equipe de vendas contempla algumas atividades, dentre elas: a) recrutar e selecionar os vendedores; b) promover treinamentos relacionados aos produtos, c) aplicar técnicas de venda e compartilhar informações institucionais; d) supervisionar o trabalho realizado; e) motivar a equipe de vendas equilibrando metas, criando bonificações e outras formas de motivação; e f) avaliar constantemente o 
desempenho individual e coletivo da equipe (KOTLER, 2000).

Inicialmente, o gestor da área de vendas tinha uma visão limitada. As principais atividades envolviam o recrutamento e a seleção de uma equipe de vendas, seguidas do treinamento, supervisão e motivação dessas pessoas. Atualmente, os executivos de vendas são reconhecidos como responsáveis pelo planejamento estratégico, pela distribuição territorial, pela análise de custos e vendas, entre outras atividades. Além disso, é responsabilidade do gerente de vendas monitorar se todas as atividades que dão suporte à venda de produtos e serviços - como produção, propaganda e distribuição - estão sintonizadas com os esforços do departamento de vendas (SPIRO; RICH; STANTON, 2009).

Embora alguns profissionais com notáveis habilidades técnicas se tornem bons gestores ou administradores, há evidências de que o talento para as vendas não está relacionado à competência para a gestão. Os mesmos fatores que formam um excelente vendedor podem prejudicar a sua atuação como gestor. Dentre as qualidades que devem ser levadas em consideração para escolha do gestor da área de vendas deve-se considerar: disposição para partilhar informações; estrutura e disciplina no trabalho; capacidade de trabalhar bem em equipe; habilidade de vendas internas; e humildade (SPIRO; RICH; STANTON, 2009).

Um fator que influencia diretamente na gestão de vendas é o ambiente de trabalho. É importante manter a equipe engajada e ciente da sua importância no atingimento das metas propostas. É parte da atribuição da gestão da área de vendas fornecer meios que propiciam o desenvolvimento do sentimento de pertencimento dos vendedores. Nesse sentido, habilidades e competências pessoais podem ser mais importantes que as técnicas e analíticas. A capacidade de desenvolver relacionamentos orientados para a equipe é muito importante. $O$ gerente de vendas deve ser sensível em relação às necessidades individuais, preocupando-se mais com a comunicação e com treinamento do que com o monitoramento e controle (SPIRO; RICH; STANTON, 2009; SILVA; VIEIRA; FAIA, 2015).

Silva, Vieira e Faia (2015), por exemplo, realizaram uma survey com 140 vendedores de lojas do varejo de material de construção civil e identificaram que o nível de controle empregado pelo gestor da área de vendas deve variar, conforme o grau de desempenho do vendedor. Os autores indicam que os gestores de vendas devem avaliar o comportamento dos vendedores individualmente, adotar sistemas de controles distintos para vendedores diferentes de uma mesma equipe de vendas e que vendedores de alta performance devem criar laços formais ou informais para transmitir sua expertise aos demais.

Alguns autores mencionam que o desempenho dos colaboradores está diretamente relacionado à sua motivação para o trabalho. A motivação para o trabalho é reconhecida como um fenômeno individual, logo não é passível de padronização. Contudo, é possível observar o comportamento motivado através de ações, sendo elas internas ou externas, que influenciam nas escolhas dos indivíduos, já que as necessidades do ser humano são construídas e manifestadas diferentemente em cada indivíduo (CHIAVENATO, 2003). Por outro lado, entende-se que o ambiente organizacional exerce influência significativa na motivação para o trabalho, aspecto que pode ser explorado pelos gestores ou líderes, a fim de engajar os colaboradores (BEZERRA; DA SILVA, 2016).

\subsection{LIDERANÇA}


Liderança pode ser definida como o processo de inspirar outras pessoas para que essas trabalhem com afinco, a fim de realizar tarefas importantes. O líder deve valorizar a diversidade, pois assim a equipe não somente aprenderá aquilo que é essencial para execução das atividades inerentes ao trabalho, mas o líder se beneficiará ao permitir que as contribuições de todas as pessoas exerçam influência na organização (SCHERMERHORN, 2006).

O líder deve ser capaz de influenciar as pessoas, motivar os indivíduos a realizarem as suas atividades além do dever, salientando o êxito do grupo. A efetividade da liderança não está relacionada ao controle do grupo e ao poder de influência, mas sim à capacidade de extrair um bom desempenho da sua equipe (BALDWIN; RUBIN; BOMMER, 2008). Consiste em conduzir um conjunto de pessoas, influenciando suas ações e comportamentos para a obtenção de desempenho compatível com os objetivos almejados (LACOMBE; HEILBORN, 2003).

A liderança também se traduz em relacionamento. Algumas vezes o relacionamento é de um para muitos, outras, de um para um. Independentemente do formato, a liderança é um relacionamento entre aqueles que aspiram liderar e aqueles que optam por seguir (GOLDSMITH; LYONS; FREAS, 2003). Logo, os líderes devem ouvir as ideias dos seus liderados, aceitar sugestões e modificar suas opiniões quando necessário (FINK; COHEN, 2003).

A construção de uma equipe engajada também é atribuição do líder. Um grupo que compreende seus objetivos e está comprometido em alcançá-los de forma compartilhada pode ser considerada uma equipe (MOSCOVICl, 2003). E a construção de uma equipe que obtém bons desempenhos continuamente configurase como um dos principais objetivos em empresas cuja atividade fim é a venda de produtos e serviços (SOUZA, 2010).

\subsection{AVALIAÇÃO DE DESEMPENHO}

Avaliação de desempenho permite identificar se há defasagem entre o comportamento do colaborador e a expectativa de desempenho da organização. A ação do gestor ou líder na avaliação de desempenho tem como objetivo conduzir uma estratégia planejada de intervenção no comportamento do avaliado, se necessário, visando melhorar o seu desempenho (LACOMBE; HEILBORN, 2003).

Avaliar 0 desempenho dos funcionários consiste em averiguar periodicamente o resultado das ações empregadas, tendo como base as funções que cada um desempenha. Deve-se considerar os resultados esperados e como os colaboradores podem contribuir para com a organização, através do seu desenvolvimento contínuo (CHIAVENATO, 1999).

São diversas as finalidades da avaliação de desempenho dos colaboradores. Em termos estratégicos pode-se citar:

- Dinamizar o planejamento da empresa;

- Aprimorar a produtividade, a qualidade e a satisfação dos clientes;

- Obter o comprometimento das pessoas em relação aos resultados desejados pela empresa;

- Melhorar a comunicação entre os níveis hierárquicos na organização, criando um clima de diálogo construtivo e eliminando dissonâncias, ansiedades e incertezas;

- Promover o desenvolvimento das pessoas na organização;

- Gerar informações que subsidiem a tomada de decisões; 


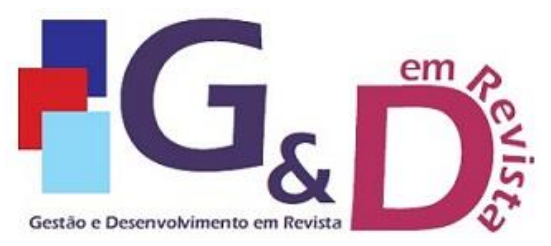

Gestão e Desenvolvimento em Revista V. 6, N. 1, jan-jun/2020, p. 46-59.

ISSN online: $2446-8738$

Artigo recebido em: 20/04/2020

Artigo aprovado em: 25/06/2020

- Estabelecer um clima de confiança, motivação e cooperação entre os membros das equipes de trabalho;

- Servir como instrumento sistematizado em decisões de carreira, sucessão, promoção, salários e participação nos resultados da empresa (PONTES, 2005).

Mesmo apresentando diversas vantagens competitivas à organização, a avaliação de desempenho pode ter impactos negativos, caso seja realizada incorretamente. Nesse sentido, Lacombe e Heilborn (2003, p. 285) descrevem as distorções mais comuns do processo de avaliação de desempenho são elas:

Subjetivismo: avaliar em função de valores e objetivos pessoais, que não coincidem com os valores, objetivos e interesses da organização.

Unilateralidade: valorizar aspectos que o avaliador julga importantes, mas que não o são para empresa ou para a posição que o avaliado ocupa.

Tendência central: medo de prejudicar os mais fracos e de assumir responsabilidades pelos mais fortes. Porque nada foi feito em relação ao mais fraco? O mais forte pode ocupar o lugar do avaliador?

Efeito Halo: atribuir ao avaliado valores positivos na maioria dos fatores se o conceito geral sobre este elemento for bom, e valores baixos aos elementos cujo conceito geral for negativo. Cada fator de avaliação deve ser analisado separadamente.

Falta de memória: ater-se apenas aos últimos acontecimentos, omitindo fatos ocorridos há mais tempo, mas dentro do período da avaliação.

Supervalorização da avaliação: acreditar que o instrumento da avaliação não contribua em nada para aproveitar o melhor dos recursos humanos.

Falta de técnica: desconhecimento das técnicas de avaliação, julgando apenas por meio do bom senso e considerando informações importantes como irrelevantes.

Existem diversos métodos e ferramentas que permitem avaliar 0 desempenho dos colaboradores, dentre eles pode-se citar:

a) Auto avaliação de desempenho: na qual o próprio colaborador avalia sua eficiência e eficácia diante do que foi estabelecido preliminarmente;

b) Avaliação pelo superior imediato: reconhecida como a forma tradicional de avaliar o desempenho dos colaboradores;

c) Avaliação superior e subordinado (por objetivos): embora similar à avaliação anterior, tem como diferencial importante $o$ fato de que o desempenho e os resultados a serem alcançados pelo avaliado são discutidos e acompanhados permanentemente por ambos;

d) Avaliação pela equipe: na qual a equipe de trabalho da qual o avaliado faz parte avalia o desempenho de cada um de seus membros e estabelece com cada um as providências necessárias para sua melhoria;

e) Avaliação $360^{\circ}$ : essa forma de avaliação envolve todas as pessoas que interferem no desenvolvimento das atividades do avaliado. Normalmente, envolve a avaliação do próprio avaliado, do supervisor do mesmo, dos colegas e pares de mesmo nível hierárquico, dos subordinados se tiver, dos clientes internos e externos, dos fornecedores, sendo, por isso, denominada avaliação $360^{\circ}$;

f) Avaliação pelo subordinado: essa é uma forma utilizada em organizações altamente democráticas e abertas ao diálogo com seus colaboradores, que permite que o avaliado ou a equipe da qual faz parte avalie seu supervisor, apontando os meios e os recursos que foram disponibilizados para que os mesmos alcançassem os seus resultados e, ainda, sugerindo melhorias em relação a maneira como o supervisor deveria agir para melhorar os resultados de todos; 
g) Avaliação por comissão: é uma forma de avaliação coletiva, em que é formada uma comissão com pessoas das diversas áreas da empresa, direta ou indiretamente ligadas ao avaliado (CHIAVENATO, 1999).

Por fim, para o bom andamento do processo de avaliação de desempenho é indispensável o feedback ao avaliado. $\mathrm{O}$ avaliado precisa saber se está atingindo os objetivos esperados ou não. Uma das características de um bom gestor é ser capaz de fazer uma boa avaliação e de saber aplicar o feedback ao subordinado (KIELWAGEN, 2013). Para alguns colaboradores um feedback positivo pode despertar o sentimento de satisfação no trabalho, o que acarreta em um melhor desempenho devido à tendência de que os trabalhadores satisfeitos realizarão as suas atividades da melhor forma possível (VESCO; BEUREN, POPIK, 2016).

\subsection{RECRUTAMENTO E SELEÇÃO DE VENDEDORES}

A seleção de vendedores engajados e comprometidos contribui para o bom desempenho da empresa. Por outro lado, o custo de recrutar e treinar novos funcionários é elevado. Logo, pode-se afirmar que o recrutamento e a seleção de vendedores são atividades chave para as empresas cuja atividade fim é a venda de produtos. Nesse sentido, Spiro, Rich e Staton (2009) descrevem que uma boa seleção é vital, porque é a força de vendas que gera os resultados organizacionais.

Em um passado recente havia uma situação econômica em que a demanda se apresentava muito maior do que a oferta, os índices de inflação eram extremamente elevados e, em comparação com os dias atuais, haviam poucos concorrentes. Esse cenário orientava os negócios para a produção, cujo objetivo principal era tornar o produto ou serviço disponível para venda - não era necessário entender todas as necessidades dos clientes, uma vez que eles tinham que se adequar aos produtos oferecidos, e isso naturalmente se refletia nas equipes de vendas, que se concentravam muito mais em conseguir os pedidos para os volumes estabelecidos pela empresa, do que em entender os clientes e satisfazer as suas necessidades (ALVAREZ; CARVALHO, 2008).

Atualmente, a situação econômica é diferente, demarcada por um mercado de alta competitividade e caracterizado pelo excesso de produção e por uma demanda cada vez mais exigente e questionadora. Esse ambiente obriga as empresas a buscar agilidade, eficiência e rapidez em suas atividades e nas relações com o mercado. O fluxo de vendas não é mais determinado pela fábrica, mas sim pela demanda do consumidor final. Dessa forma, independentemente do lugar que ocupem na cadeia de negócios, as empresas precisam direcionar as suas ações para conquistar a preferência dos consumidores. Os profissionais que passaram a atuar nesse novo ambiente devem entender essas mudanças e buscar compreender as necessidades dos clientes. No mercado de $\mathrm{Tl}$, o contexto não é diferente. $\mathrm{A}$ competitividade é elevada e a busca por profissionais qualificados é constante, enaltecendo a importância do recrutamento e seleção (ALVAREZ; CARVALHO, 2008; BAGAGI, 2016).

\section{METODOLOGIA}

O método de estudo de caso foi empregado nesta pesquisa, a fim de compreender uma realidade empresarial em profundidade. A empresa escolhida como unidade de análise é a Mazer Distribuidora de Tecnologia Ltda. A empresa 
atua no ramo de Tecnologia de Informação - TI, mais especificamente na distribuição de equipamentos de informática.

A Mazer iniciou as suas atividades em 27 de junho de 1997. É reconhecida como uma das principais distribuidoras na Região Sul do Brasil e atua nos mercados das regiões Sudeste, Centro-Oeste e Nordeste. O foco da empresa é a distribuição de produtos como computadores, notebooks, smartphones, tablets, TVs, peças, produtos para integração, suprimentos, periféricos, acessórios e etc.. Atende os segmentos Corporativo, Consumer, Componentes, Automação Comercial, Suprimentos, TV\&Imagem, Conectividade, Acessórios, CFTV, Mobile e Gamer (MAZER, 2020).

A empresa possui três filiais, nos Estados do Paraná, Santa Catarina e Rio Grande do Sul. A pesquisa foi realizada na filial do Rio Grande do Sul, a qual é responsável pelo maior volume de faturamento da empresa e pelo maior número de colaboradores atuantes na área de vendas.

Quando a pesquisa foi realizada a área de vendas era composta por 30 vendedores. A amostra disponibilizada para análise contempla resultados da avaliação de desempenho de quinze (15) vendedores com mais de quatro anos de empresa, os quais possuem carteiras de clientes homogêneas. O nível de escolaridade dos vendedores analisados é variado, pois apenas quatro (4) têm o nível superior completo, cinco vendedores estão cursando a Graduação e sete (7) têm o Ensino Médio completo. No que se refere ao ambiente de trabalho, os vendedores estão distribuídos em uma única sala, sentados lado a lado, em quatro filas, em frente ao seu gestor.

A coleta dos dados contemplou a análise de documentos que formalizam o plano de cargos e salários da empresa. Posteriormente, foi disponibilizado um questionário e os resultados da avaliação de desempenho proposta por esse questionário no ano de 2013 - primeira edição do processo de avaliação de desempenho neste formato. O formulário utilizado para avaliação de desempenho pela organização contempla 12 categorias, são elas: Conhecimento do Trabalho (CT), Negociação (NEG), Comunicação (COM), Relacionamento (REL), Automotivação (AUT), Gerenciamento da Carteira de Clientes (GCC), Produtividade (PROD), Comprometimento (CO), Aprendizagem (APR), Apresentação Pessoal $(A P)$, Organização (ORG) e Resultados (RES).

As avaliações de desempenho terão periodicidade semestral e os vendedores serão avaliados por todas as onze (11) gerências: Vendas, Compras, Tl, Recursos Humanos, Financeiro, Fiscal, Logística, Cobrança, Retorno de Mercadoria Avariada - RMA, Marketing e Desenvolvimento.

Os dados obtidos foram organizados e tabulados, a fim de identificar o desempenho individual e coletivo dos vendedores. Para sintetizar os resultados, a estatística descritiva foi empregada, o que permitiu calcular a média das avaliações por colaborador e por categoria, bem como os níveis mínimo e máximo em cada categoria de avaliação e a dispersão entre as notas atribuídas (BUSSAB; MORETTIN, 2003).

Durante a coleta dos dados a técnica de observação participante foi empregada para compreender a dinâmica de trabalho da área comercial e as características da cultura organizacional (RICHARDSSON, 1999). Também foi possível realizar uma entrevista com a gestora da equipe de vendas, a qual atua nesta empresa, nesta mesma função, há 16 anos.

A literatura foi utilizada como base para construção do roteiro da entrevista, 
momento no qual foi discutido, em especial, o detalhamento de como as avaliações de desempenho são realizadas e como se dá o feedback e o acompanhamento dos vendedores com desempenho aquém e além do esperado.

\section{ANÁLISE E DISCUSSÃO DOS RESULTADOS}

$\mathrm{Na}$ avaliação de desempenho o vendedor pode receber notas de 1 (um) a 5 (cinco), sendo um a menor nota e cinco a maior nota. Existem cinco escalas para avaliação de cada elemento: Nada atendido; Minimamente atendido; Parcialmente atendido, Atendido e Superou o esperado; além do item: Não se aplica. A organização considera que 0 vendedor deve obter uma nota igual ou superior a 3,5 em cada elemento para que a categoria seja considerada como atendida.

$\mathrm{Na}$ Tabela 1 a seguir apresenta-se o resultado da avaliação de desempenho dos vendedores no primeiro semestre do ano de 2013, considerando o resultado médio obtido em cada uma das categorias e a média global de desempenho de cada vendedor. Os colaboradores avaliados foram apresentados em ordem decrescente em termos de desempenho médio, omitindo informações pessoais dos mesmos.

As notas iguais ou inferiores a 3,0 foram destacadas na cor vermelha e as notas iguais ou superiores a 4,5 foram destacadas na cor azul para facilitar a identificação das observações atípicas. Por fim, apresentam-se algumas medidas estatísticas que auxiliam na sumarização dos achados: média, desvio padrão, valor mínimo e valor máximo.

Tabela 1 - Resultado da Avaliação de Desempenho

\begin{tabular}{|c|c|c|c|c|c|c|c|c|c|c|c|c|c|}
\hline Vendedores & CT & NEG & COM & REI & AUT & GCC & PROD & $\mathrm{CO}$ & APR & $\mathbf{A P}$ & ORG & RES & Média \\
\hline Vendedor 9 & 4,39 & 4,46 & 4,42 & 4,42 & 4,40 & 4,00 & 4,00 & 4,47 & 4,17 & 4,50 & 4,50 & 4,25 & \\
\hline Vendedor 2 & 4,16 & 4,36 & 4,38 & 4,47 & 4,44 & 4,38 & 3,83 & 4,47 & 4,33 & 4,00 & 4,33 & 4,25 & 4,28 \\
\hline Vendedor 15 & 4,24 & 2,23 & 4,29 & 4,33 & 4,14 & 4,38 & 4,00 & 4,13 & 4,17 & 4,50 & 4,33 & 3,50 & 4,02 \\
\hline Vendedor 5 & 4,24 & 4,38 & 4,40 & 4,37 & 4,03 & 4,13 & 3,50 & 4,27 & 4,17 & 4,50 & 4,50 & 3,50 & 4,17 \\
\hline Vendedor 14 & 4,34 & 4,15 & 4,17 & 3,98 & 3,87 & 3,63 & 3,67 & 4,07 & 3,83 & 4,50 & 3,83 & 4,00 & 4,00 \\
\hline Vendedor 13 & 4,41 & 4,17 & 4,29 & 4,21 & 3,97 & 3,50 & 3,33 & 3,93 & 4,17 & 4,50 & 4,00 & 3,50 & 4,00 \\
\hline Vendedor 1 & 4,19 & 4,00 & 3,89 & 2,88 & 3,85 & 4,42 & 4,17 & 3,38 & 3,67 & 4,00 & 4,17 & 3,75 & 3,86 \\
\hline Vendedor 6 & 4,11 & 4,12 & 3,95 & 3,63 & 3,86 & 3,63 & 3,67 & 3,93 & 3,17 & 4,00 & 4,00 & 3,50 & 3,80 \\
\hline Vendedor 12 & 4,14 & 4,08 & 4,08 & 4,18 & 4,06 & 3,63 & 2,33 & 3,53 & 3,67 & 4,00 & 3,83 & 3,33 & 3,74 \\
\hline Vendedor 7 & 4,24 & 4,23 & 4,17 & 4,00 & 3,21 & 3,13 & 2,50 & 4,00 & 3,17 & 4,50 & 4,33 & 2,75 & 3,69 \\
\hline Vendedor 10 & 3,52 & 3,85 & 3,98 & 3,67 & 3,31 & 4,00 & 3,33 & 2,93 & 3,33 & 3,50 & 3,67 & 3,25 & 3,53 \\
\hline Vendedor 8 & 4,03 & 3,85 & 3,83 & 3,39 & 3,33 & 3,25 & 2,67 & 3,07 & 3,50 & 3,50 & 3,67 & 3,50 & 3,47 \\
\hline Vendedor 4 & 3,89 & 3,92 & 4,02 & 3,87 & 3,29 & 3,25 & 2,33 & 3,67 & 3,67 & 4,50 & 3,83 & 2,67 & 3,58 \\
\hline Vendedor 3 & 3,76 & 3,50 & 3,57 & 3,50 & 3,63 & 3,00 & 3,17 & 3,69 & 3,00 & 3,00 & 3,67 & 3,25 & 3,40 \\
\hline Vendedor 11 & 3,97 & 3,62 & 3,78 & 3,52 & 3,03 & 3,25 & 2,00 & 3,20 & 2,83 & 3,50 & 3,83 & 2,75 & 3,27 \\
\hline Mínimo & 3,52 & 2,23 & 3,57 & 2,88 & 3,03 & 3,00 & 2,00 & 2,93 & 2,83 & 3,00 & 3,67 & 2,67 & 3,27 \\
\hline Máximo & 4,41 & 4,46 & 4,42 & 4,47 & 4,44 & 4,42 & 4,17 & 4,47 & 4,33 & 4,50 & 4,50 & 4,25 & 4,33 \\
\hline Média & 4,11 & 3,93 & 4,08 & 3,89 & 3,76 & 3,71 & 3,23 & 3,78 & 3,66 & 4,07 & 4,03 & 3,45 & 3,81 \\
\hline Desvio padrão & 0,24 & 0,54 & 0,25 & 0,46 & 0,44 & 0,48 & 0,70 & 0,49 & 0,48 & 0,50 & 0,30 & 0,49 & 0,32 \\
\hline
\end{tabular}

Analisando os resultados obtidos de forma global, é possível perceber que as categorias: Produtividade $(3,23)$ e Resultados $(3,45)$ são aqueles cuja média de avaliação figura nos menos níveis. Salienta-se que os resultados são inferiores ao padrão mínimo de desempenho esperado pela empresa $(3,50)$. Além de obter o menor índice de avaliação média, a categoria Produtividade também apresentou a maior dispersão, tendo um desvio padrão de 0,70 e notas significativamente baixas para alguns vendedores $(2,00 ; 2,33,2,50,2,67)$.

As categorias Apresentação Pessoal e Organização são aquelas em que os 
vendedores obtiveram as melhores notas, tendo uma média de 4,50 . As categorias Negociação $(4,46)$, Relacionamento $(4,47)$ e Comprometimento $(4,47)$ também obtiveram destaque.

O desempenho médio da amostra varia entre 4,33 (Vendedor 9) e 3,27 (Vendedor 11). Além da dispersão percentual de 1,06 pontos entre os dois extremos há de se considerar que os Vendedores ํo. $3(3,40)$ e $11(3,27)$ não atingiram 0 desempenho esperado, obtendo uma avaliação média inferior a 3,50. Dito de outra forma, aproximadamente $86 \%$ dos vendedores atingiram o desempenho mínimo desejado, pois apenas dois vendedores têm um desempenho inferior a 3,50 métrica utilizada pela organização para definir o nível mínimo de desempenho esperado.

É possível observar um alinhamento em relação às categorias Conhecimento do Trabalho e Comunicação dada a baixa variabilidade entre as avaliações atribuídas (desvio padrão: 0,24 e 0,25). Essa característica pode estar relacionada ao tempo em que os colaboradores atuam na empresa, já que todos tinham mais de 4 anos de experiência na organização, nesta mesma função, quando a avaliação foi realizada.

Considerando a importância de complementar a análise dos dados secundários obtidos com dados qualitativos que permitem compreender o contexto no qual a avaliação de desempenho foi realizada e os fatos que antecederam e sucederam a avaliação, foi realizada uma entrevista com a gerente de vendas, responsável pelo acompanhamento do desempenho obtido pelos vendedores e pelo feedback da avaliação de desempenho.

Além dos critérios metodológicos mencionados, que justificam a realização da entrevista, a literatura descreve que o líder deve apresentar e representar os objetivos da organização. Envolver os liderados, a fim de que esses persigam os objetivos propostos (BERGAMINI, 2009).

É importante mencionar que a entrevistada demonstrou interesse em colaborar com a pesquisa. Descreveu que os indicadores avaliados servem de balizadores para os vendedores guiarem as suas ações. A conduta esperada dos vendedores está alinhada à literatura, visto que a empresa entende que eles devem desenvolver uma visão de negócios, não se concentrar apenas nos produtos, mas em serem especialistas no que diz respeito aos seus clientes, concentrando seu foco não apenas na venda, mas sim na conquista e desenvolvimento dos clientes (ALVAREZ; CARVALHO, 2008).

A gerente conduziu o feedback da avaliação de desempenho e mencionou que há uma grande expectativa em relação a esse momento por parte dos vendedores. Muitos deles já sabem o que vai ser dito, pois têm consciência de seu desempenho atual. Depois de fornecido o feedback, os vendedores que obtiveram o pior desempenho ficam sob análise frequente da gerente de vendas. Caso não apresentem uma melhora significativa nos meses seguintes eles estarão sujeitos ao desligamento.

A entrevistada relatou que possui uma análise detalhada do perfil dos vendedores que não conseguem atingir o desempenho esperado. Dentre as medidas de acompanhamento e controle empregadas pela empresa, pode-se citar: a) escutas telefônicas das ligações com clientes e demais colaboradores; b) conversas individuais; c) monitoramento de máquina; d) sugestões de mudanças; e e) correção de rota. Se, após todas as intervenções descritas, o vendedor ainda não se alinhar aos objetivos da empresa, então será realizada uma entrevista de 


\section{desligamento.}

Os resultados obtidos evidenciam que a empresa têm extraído bons resultados da sua equipe de vendas, já que aproximadamente $86 \%$ dos vendedores atingiram o desempenho mínimo desejado. A gestão da área de vendas também tem adotado estratégias que estão alinhadas à teoria, que envolvem o controle e monitoramento dos vendedores, bem como a realização de feedbacks continuamente. Durante a observação participante foi possível perceber que a equipe completa, composta por trinta (30) vendedores, é engajada e comprometida, principalmente quando ações promocionais são lançadas e envolvem bonificações e remunerações adicionais.

Por fim, deve-se considerar as características da cultura organizacional na discussão dos resultados obtidos, pois a empresa não adota uma política de desligamento imediato se os vendedores não atingem o desempenho esperado em um determinado mês. Caso isso ocorra, o desempenho do colaborador será acompanhado e reavaliado ao longo do tempo. Acredita-se que esse posicionamento deve-se à gestão familiar da organização, a qual valoriza mais os vínculos (relacionamentos) que os resultados (GOLDSMITH; LYONS; FREAS, 2003).

\section{CONSIDERAÇÕES FINAIS}

Essa pesquisa teve como objetivo identificar os fatores que influenciaram no desempenho da área comercial da empresa Mazer Distribuidora de Tecnologia Ltda., que atua no segmento de TI, mais precisamente na distribuição de equipamentos de informática.

O objetivo foi atendido através da análise da avaliação de desempenho de uma amostra de 15 vendedores, realizada no primeiro semestre do ano de 2013. A avaliação de desempenho foi realizada pelas onze (11) gerências da empresa: Vendas, Compras, TI, Recursos Humanos, Financeiro, Fiscal, Logística, Cobrança, Retorno de Mercadoria Avariada - RMA, Marketing e Desenvolvimento, e contempla doze (12) categorias de avaliação: Conhecimento do Trabalho (CT), Negociação (NEG), Comunicação (COM), Relacionamento (REL), Automotivação (AUT), Gerenciamento da Carteira de Clientes (GCC), Produtividade (PROD), Comprometimento (CO), Aprendizagem (APR), Apresentação Pessoal (AP), Organização (ORG) e Resultados (RES). A fim de complementar a análise e discussão dos dados obtidos através do questionário de avaliação de desempenho, uma entrevista com a gestora da área de vendas foi realizada, buscando compreender como as avaliações de desempenho são realizadas e como se dá o feedback e o acompanhamento dos vendedores com desempenho aquém e além do esperado.

Foi possível identificar que os fatores que mais influenciaram positivamente no desempenho dos vendedores analisados são: Apresentação Pessoal $(4,50)$, Organização $(4,50)$ Relacionamento $(4,47)$, Comprometimento $(4,47)$ e Negociação $(4,46)$. Já os fatores Produtividade $(3,23)$ e Resultados $(3,45)$ são aquelas categorias cuja influência negativa no desempenho foi maior.

De forma global, entende-se que a empresa têm extraído bons resultados da sua equipe de vendas, já que aproximadamente $86 \%$ dos vendedores atingiram o desempenho mínimo desejado. A gestão da área de vendas também tem adotado estratégias que estão alinhadas à teoria, que envolvem o controle e monitoramento 
dos vendedores, bem como a realização de feedbacks continuamente. A gestão e acompanhamento dos vendedores com desempenhos aquém do esperado é realizada de forma acolhedora, característica que pode ser atribuída à gestão familiar da organização, que prioriza os vínculos (relacionamentos) em detrimento dos resultados.

Por fim, é importante mencionar que embora tenham sido disponibilizados dados de apenas $50 \%$ dos vendedores da área comercial, trata-se de um grupo bastante heterogêneo em termos de idade, gênero, formação acadêmica e profissional. Contudo, essas informações não puderam ser discutidas nesta pesquisa, porque a organização não autorizou a divulgação de tais dados. Outra limitação da pesquisa refere-se à acessibilidade aos dados, o que restringiu a amostra pesquisada à equipe de vendas de uma das filiais, além de não ter acesso à avaliação de desempenho de anos anteriores, visto que a organização implementou o processo de avaliação de desempenho neste formato no ano de 2013, cujos resultados seriam analisados, a fim de avaliar a continuidade.

Em estudos futuros seria oportuno incluir a percepção alta direção da empresa sobre o processo de avaliação de desempenho dos colaboradores, a fim de compreender a expectativa de impacto do processo de avaliação no desempenho futuro dos avaliados. Da mesma forma, seria importante compreender se os avaliados são receptivos e reconhecem o processo de avaliação de desempenho como algo positivo, contínuo e formativo.

\section{REFERÊNCIAS}

ALVAREZ, Francisco Javier S. Mendizabal.; CARVALHO, Marcos R. Gestão eficaz da equipe de vendas. 1. ed. São Paulo: Saraiva, 2008.

BAGAGl, Moisés. Como Anda a Produtividade na Sua Empresa? Revista PartnerSales. Edição 91, Ano 9, 2016.

BALDWIN, Timothy; RUBIN, Robert; BOMMER, William. Desenvolvimento de Habilidades Gerenciais. Rio de Janeiro: Elsevier, 2008.

BERGAMINI, Cecilia Whitaker. Administração do Sentido. 1. ed. São Paulo: Atlas, 2009.

BEZERRA, I. V.; DA SILVA, E. L. Campanhas de Incentivo à Vendas como Fator de Motivação Organizacional. Revista Educação, Gestão e Sociedade, Ano 6, №. 22, p. 1-17, 2016.

BUSSAB, W.O; MORETTIN, P.A. Estatística básica. São Paulo: Editora Saraiva, 2003.

Gestão de pessoas: o novo papel dos recursos humanos nas organizações. 14. ed. Rio de Janeiro: Campus, 1999.

CHIAVENATO, Idalberto. Administração Estratégica. São Paulo: Ed. Saraiva, 2003. 


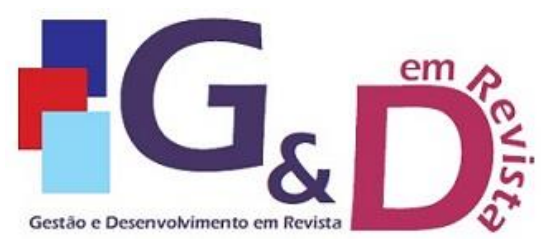

Gestão e Desenvolvimento em Revista V. 6, N. 1, jan-jun/2020, p. 46-59.

ISSN online: $2446-8738$

Artigo recebido em: 20/04/2020

Artigo aprovado em: 25/06/2020

CHIQUIE, Marco Antônio. A força da equipe comercial no Distribuidor de TI. Abradisti, 2011. Disponível em: <https://itforum365.com.br/a-forca-da-equipecomercial-no-distribuidor-de-ti/>. Acesso em: 13 de maio de 2020.

FERREIRA, Rony Santos; FRANCO, Fabiana. O PAPEL DO LIDER NA MOTIVAÇÃO DE UMA EQUIPE DE VENDAS. Revista de Administração e Contabilidade - RAC, [S.I.], v. 2, n. 4, set. 2015.

FINK, Stephen L.; COHEN, Allan R. Comportamento organizacional. 10. ed. São Paulo: Atlas 2003.

FUTRELL, Charles. Vendas: fundamentos e novas práticas de gestão. 1. ed. São Paulo: Saraiva, 2003.

GENISELLI, André. CES 2017: Celebrando a História e o Futuro da Tecnologia. Revista PartnerSales, edição 96, Ano 10, p. 38-41, Janeiro-Fevereiro, 2017.

GAMBARDELLA, A., PANICO, C., VALENTINI, G. Strategic incentives to human capital. Strategic Management Journal, 36(1): 37-52, 2015.

GOLDSMITH, Marshall; LYONS, Laurence; FREAS, Alyssa. Coaching: o exercício da liderança. 10. ed. Rio de Janeiro: Elsevier, 2003.

GORDINHO, Mariano. ABRADISTI - Presença Regional das Revendas: Oportunidades de Distribuição nos Quatro Cantos do País. Revista Eletrolar, Ano 15, ํo. 97, 2014.

KIELWAGEN, Edson Klaus. Gestão de pessoas. Indaial SC: Ed. Uniasselvi, 2013.

KOTLER, Philip. Administração de marketing: a edição do novo milênio. 10. ed. São Paulo, 2000.

LACOMBE, Francisco José Masset; HEILBORN, Gillberto Luiz José. Administração: Princípios e Tendências. São Paulo: Saraiva, 2003.

MAZER. Mazer Distribuidora. Disponível em: $<$ https://www.mazer.com.br/institucional/sobre-a-mazer>. Acesso em: 06 de maio de 2020.

MOSCOVICl, Fela. Equipes dão certo: a multiplicação do talento humano. 12. ed. Rio de Janeiro: José Olympio, 2003.

MLLER, D., XU, X., MEHROTRA, V. When is human capital a valuable resource? The performance effects of Ivy League selection among celebrated CEOs. Strategic Management Journal, 36(6): 930-944, 2015.

PONTES, Benedito Rodrigues. Avaliação de Desempenho: nova Abordagem. 9. ed. São Paulo: LTR, 2005. 


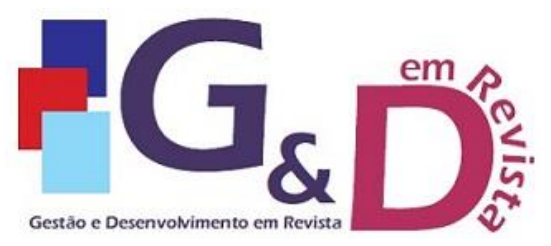

Gestão e Desenvolvimento em Revista V. 6, N. 1, jan-jun/2020, p. 46-59. ISSN online: $2446-8738$ Artigo recebido em: 20/04/2020 Artigo aprovado em: 25/06/2020

RICHARDSON, Roberto Jarry. Pesquisa Social Métodos e Técnicas. 3. ed. São Paulo: Atlas, 1999.

SCHERMERHORN, John R. Administração: Conceitos Fundamentais. Rio de Janeiro: LTC, 2006.

SILVA, J. D.; VIEIRA, V. A.; FAIA, V.S.. Quando o Sistema de Controle Enfraquece o Desempenho com Vendas. Revista Brasileira de Marketing, Vol. 14. №. 1, p. 1-17, 2015.

SOUZA, Vital. Liderança, desenvolvimento de equipes de trabalho e personalidade. Adminstradores - O Portal de Administração. São Paulo, 2010. Disponível em: <http://www.administradores.com.br/informe-se/artigos/liderancadesenvolvimento-de-equipes-de-trabalho-e-personalidade/49934/>. Acesso em 06 de maio de 2020.

SPIRO, Rosann L.; RICH, Gregory A.; STANTON, William J. Gestão da força de vendas. 12. ed. São Paulo: McGraw-Hill, 2009.

STARR, E., GANCO, M., CAMPBELL, B.A. Strategic Human Capital Management in the Context of Cross-Industry and Within-Industry Mobility. Strategic Management Journal, 39 (8), 2226-2254, 2018.

VESCO, D. C. D.; BEUREN, I. M.; POPIK, F. Percepção de justiça na avaliação na avaliação de desempenho e satisfação do trabalho. Enfoque: Reflexão Contábil, vol. 35, no. 3, p. 121-138, 2016.

VOMBERG A., HOMBURG, C., BORNEMANN, T. Talented people and strong brands: the contribution of human capital and brand equity to firm value. Strategic Management Journal 36(13): 2122-2131, 2015. 